\title{
ESTIMATION OF THE CZECH REPUBLIC SACRIFICE RA- TIO FOR THE TRANSITION PERIOD
}

\author{
Roman HUŠEK, Tomáš FORMÁNEK*
}

\begin{abstract}
:
Estimation of the costs of disinflation policy is usually done using the sacrifice ratio (SR) coefficient. This paper provides two alternative estimates of SR for the Czech economy. The estimates are based on relatively simple, but transparent and verified models, i.e. their vector autoregression and vector moving average representations. When we analysze our estimates of the Czech SR from the accuracy point of view, we see that the results are very sensitive to the way of definition of monetary shocks. Even though the individual estimates of the SR are generally not accurate enough for monetary policy decision making, there is a good probability that the Czech SR was negative during the transition period analysed, with relatively low absolute value. We may therefore assume that if the Czech National Bank decides to incur monetary restriction, such action would not have long-term significant negative impact on output.
\end{abstract}

Keywords: sacrifice ratio, impulse response (IR) function, Blanchard-Quah decomposition

JEL Classification: C32, E31, E52

\section{Introduction}

Regardless of the type of operational framework applied by the central bank, restrictive monetary policy actions are usually associated with subsequent output loss, i.e. with relatively persistent decrease of the real gross domestic product (GDP) or its growth, that follows after the restrictive policy measure. Therefore, the timing and extent of disinflation policy are decided by the central bank upon weighting the expected benefits of such action against its expected costs (decline of the GDP growth rate).

The estimation of the costs of disinflation policy is usually performed (see Gali, 1992 or Cecchetti and Rich, 1999) using the sacrifice ratio (SR) coefficient, which is defined as cumulative loss in output, measured as a per cent of one-year GDP, associated with a one percentage point of permanent reduction in the inflation rate. The estimation of output loss due to anti-inflation policy is the main purpose of this

*) University of Economics, 4, W. Churchill Sq., CZ - 13067 Prague 3 (e-mail: husek@ vse.cz). 1299.

$\left.{ }^{\star \star}\right)$ This paper is a part of the research project of the Grant Agency of the Czech Republic No. 402/03/ 
paper. We aim to analyse and assess the possible effect of disinflation monetary policy on the inflation and real GDP. The main potential reasons for such future restrictive monetary measures are - among others - as follows: non-compliance with the monetary stability requirements in the period before the Exchange Rate Mechanism (ERM2) accession, non-compliance with the Maastricht criteria, unexpected asymmetric shocks, etc.

Also, there is one more important reason for struggling to estimate the SR, which closely relates to inflation targeting. Assuming that the three most important factors influencing the SR value are the credibility of monetary policy, expectations formation type and the nominal intertia of the economy, we may use the SR as a proxy variable to describe the total nominal inertia of the economy analysed. Higher values of nominal inertia (ceteris paribus - at a given level of central bank credibility and for the given expectations type) lead to a less favourable trade-off between price stability and real output growth. Practical usability of the SR coefficient for monetary policy formation depends on the accuracy of the SR estimate. However, in this particular area we find most of the weaknesses of the approach described.

\section{Theoretical Background for the Estimation of Expected Gross Domestic Product Loss}

Transmission mechanisms leading to high SR values are based on neo Keynesian macroeconomic theory (see e.g. Taylor, 1979). Market subjects (firms) therefore set their prices according to the expected price level and also according to the expected monetary policy. If firms prefer not to diverge their prices from their relevant competition, they will react more slowly to changes in monetary policy. However, expectations formation has a crucial role on the SR value. Suppose that firms form their expectations rationally (forward looking expectations) and that they expect forthcoming restrictive monetary policy. In such case, firms would opt to adjust their prices for any (ceteris paribus given) nominal inertia in the economy. Therefore, the final price flexibility may be relatively high and monetary restriction may have a relatively low negative impact on real output. On the other hand, if expectations are formed adaptively (backward looking expectations), price changes are slow and SR therefore rises accordingly: because the inflation is persistent, monetary restriction has small impact on prices and high impact on output. Further analysis of adaptive expectations transmission mechanism in relation with the SR coefficient was performed by Fuhrer (1995).

If rational expectations play a significant role in the price setting process, monetary policy credibility is also an important factor influencing the SR value. Although the logic of the processes involved implies an inverse relationship between SR and credibility, a real "credibility premium" is not widely supported by econometric studies (see Leitemo and Røste, 2003). Nevertheless, the concept of credibility premium leads us to costless disinflation with $\mathrm{SR}=0$, that is backed by the neoclassical macroeconomy, where under rational expectations a credible disinflation target may be reached virtually immediately and without changes or losses in real output. We may therefore conclude that adaptive estimation forming process inevitably leads to positive SR values, whereas under rational expectations any positive value of SR is conditioned by imperfect credibility of monetary policy.

Using a simple macroeconomic model published by Ball (1999), we may derive the SR for a small open economy (see also Leitemo and Røste, 2003). As the following model is built on unobservable macroeconomic variables, it has only an illustrative value for the Czech transitive economy. The model and the subsequent SR derivation are based on a simplifying assumption that subjects form their expectati- 
ons adaptively (with the exception of subjects on financial markets). Therefore future monetary policy actions have no direct influence on firms setting their prices on goods markets. The three-equation macroeconomic model of a small open economy used for the SR derivation is set as follows (see Ball, 1999):

$$
\begin{gathered}
\pi_{t+1}=\pi_{t}+\gamma y_{t}+\theta\left(e_{t}-e_{t-1}\right)+\varepsilon_{t+1}, \\
y_{t+1}=\rho y_{t}-\alpha r_{t}+\beta e_{t}+u_{t+1}, \\
e_{t}=E_{t} e_{t+1}-r_{t}, \\
\text { and } e_{t} \equiv s_{t}+p_{t}^{f}-p_{t}
\end{gathered}
$$

where $\pi_{t}$ - inflation measured as difference of two consecutive logs of price level $\pi_{t}$ $=p_{t}-p_{t-1}, y_{t}$ - output gap, $E_{t}-$ random exogenous price level shock, $e_{t}-$ real exchange rate, $r_{t}$ - real interest rate, $u_{t}$ - random exogenous demand shock, $E_{t} e_{t+1}-$ expected value of the variable $e$ as in period $t+1$, generated by financial market subjects upon all information available at time $t, s_{t}-$ nominal exchange rate, $p_{t}, p_{t}^{f}-$ local and foreign price levels, $\gamma, \theta, \rho, \alpha, \beta$ - model coefficients.

Variables in the model (1) to (3) are measured in logs and as deviations from their long-term equilibrium (unconditional expectations), with the exception of inflation and real interest rate (measured in percentage points p.a.).

Equation (1) represents the Phillips curve for an open economy. Inflation in this equation is fully persistent and reacts (after one lag) to aggregate demand and exchange rate changes. The equation (2) is an equivalent of dynamic IS curve. Output in this equation is also persistent, with degree of persistence given by the coefficient $\rho$, and it is influenced by lagged changes in exchange rate and interest rate. Equation (3) represents the uncovered real interest rate parity condition, i.e. asset revenues are constantly equalized on international markets. According to macroeconomic theory, subjects on financial markets are supposed to form their expectations rationally. Within the economy as described by the model (1) to (3), the real interest rate acts as the sole instrument of central bank's monetary policy. This is a significant simplification, however, the information loss or deviation from reality is easily bearable, as the nominal interest rate (influenced by the central bank in real economies) is a sum of real interest rate and expected inflation (given the rational expectations forming by central bank).

Monetary transmission mechanisms of the model (1) to (3) may be described using a simple example. A single exogenous shock increasing the level of interest rate $r_{t}$ decreases the aggregate demand by two transmission channels: direct decrease of future consumption is implemented in the equation (2); simultaneously to this effect the foreign exchange rate is appreciated, i.e. domestic goods get relatively more expensive than foreign goods. The value of $e_{t}$ is set according to the rational expectations hypothesis valid for financial markets, therefore the interest rate affects the exchange rate both immediately (through the current interest rate differential) and in the future (through expected interest rate differentials). Subsequently inflation is influenced as a consequence of change in $r$ (monetary policy change) through both transmission channels: lower aggregate demand decreases inflation in the next period (see equation (1)); at the same time inflation is affected by the exchange rate, i.e. by its influence on local currency prices of imported foreign goods.

We suppose that within the model (1) to (3) monetary policy is performed by the central bank effectively, given its operational framework which in this case is inflati- 
on targeting. For our model, we now may define the objective function of the central bank as follows:

$$
\min _{\{\}_{t}^{\infty}} \rightarrow U_{C B}=E_{t} \sum_{i=0}^{\infty} \delta^{i}\left(\left[\pi_{t, i}-\pi^{*}\right]^{2}+\lambda y_{t, i}^{2}\right) ; \lambda \geq 0
$$

where $\pi^{*}$ - inflation target, $\delta$ - discount factor, $\lambda$ - relative weight assigned to output stabilization.

The model (1) to (3) and the objective function (4) give basis for discretionary monetary policy. Optimal level of the interest rate (the sole tool of monetary policy) may now be written as

$$
r_{t}^{*}=\phi_{\mathrm{p}} \pi_{t}+\phi_{y} y_{t}+\phi_{e} e_{t-1}
$$

where coefficients $\phi$ of the central bank's reaction function (5) are linear functions of coefficients from the model (1) to (3) and the objective function (4). Analytical computation of the individual $\phi$-coefficients of the optimal discretionary policy is skipped here because of its complexity (due to lags within the transmission mechanisms) and because of its low contribution to the SR theoretical derivation from the model presented (for details see e.g. Leitemo and Røste, 2003).

Allowing for exogenous unsystematic shocks affecting the optimal monetary policy at time $t$, we may rewrite the variable $r_{t}$ from the model (1) to (3) as

$$
r_{t}=r_{t}^{\star}+\xi_{t}
$$

where $\xi_{t}$ is a white noise exogenous shock that affects the interest rate (monetary policy). Real exchange rate is the only variable in our model that has future value expectations formed according to the rational expectations hypothesis. Allowing for shocks to monetary policy (6), we may also write

$$
e_{t}=v_{\mathrm{p}} \pi_{t}+v_{y} y_{t}+v_{e} e_{t-1}-\xi_{t}
$$

where coefficients $v$ are again linear functions of the coefficients from the model (1) to (4). Again, we skip the analytical derivation of $v$-coefficients for the same reason we did so with $\phi$-coefficients from the equation (5).

We may now use real or simulated data in order to estimate the model (1) to (3) and look for optimal solutions according to the criteria (4). Nevertheless, this complex process would not provide us with further insight to the SR derivation. We shall therefore follow Ball (1999) and Leitemo and Røste, (2003) and use calibrated values for the coefficients: $\rho=0.8, \gamma=0.4, \theta=0.2, \alpha=0.6$ and $\beta=0.2$; variance of the random shocks is set to $\sigma_{e}^{2}=\sigma_{u}^{2}=0.5$ and we assume the discount factor in the objective function (4) to be $\delta=0.97$ (which corresponds to a generally used approximation of long-term equilibrium of real interest rate of $3 \%$ p.a.). The relative weight put by central bank to output is set to $\lambda=0.5$.

Based on the calibrated model as described and using the transmission mechanisms discussed, we may now use an disinflation experiment to illustrate disinflation costs and to derivate the SR coefficient. Lets assume the following situation: the economy as described by equations (1) to (3) is at its long-term equilibrium and the central bank decides (in an arbitrarily set time period $t_{0}=1$ ) to lower its inflation target by one percentage point: $\Delta \pi^{*}=-0.01$. As inflation at $t_{0}=1$ is equal to the original inflation target, the immediate result of central bank's target lowering is the relative "increase" of the inflation $\pi_{t}$ against the new target. Central bank reacts to this situation by changing the interest rate $r_{t}^{*}$ according to (5).

Graphs 1 and 2 represent the expected behaviour of the variables in the model after change in the inflation target setting (see Leitemo and Røste, 2003). The in- 
terpretation of the graphs shown below is as follows: in reaction to a change of inflation target the central bank raises real interest rate, which (immediately) appreciates the exchange rate - this happens during the period $t_{0}=1$. Change of interest rate and exchange rate during the period will cause output to fall in the next period: $t=2$ (see equation (2)). The exchange rate appreciation in $t_{0}=1$ leads to decrease of inflation in $t=2$ (see equation (1)). As for inflation, the depreciation of the exchange rate between $t_{0}=1$ and $t=2$ is outweighed by the output gap influence. The exchange rate subsequently keeps appreciating constantly from the period $t=2$ as a consequence of negative real interest rate. The output gap is gradually decreasing and at the same time inflation rate approaches its new long-term equilibrium (inflation target). Inflation target is reached at the same moment when output gap closes.

Graph 1

Sacrifice Ratio Derivation (a)

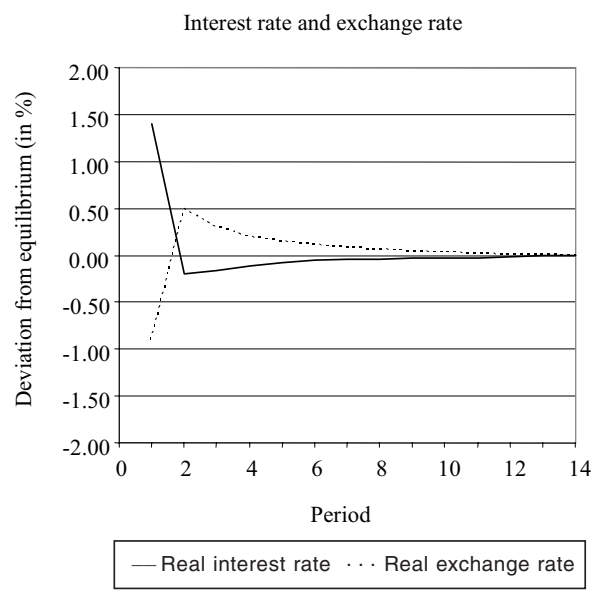

Graph 2

Sacrifice Ratio Derivation (b)

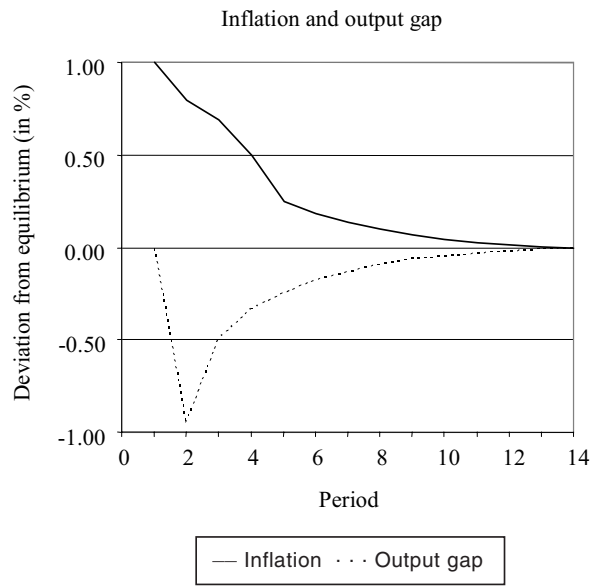

As we have already stated, SR is defined as cumulative output loss under disinflation, relative to potential output. Using the equations (1) to (4) it is now possible to formalise the SR coefficient (see Leitemo and Røste, 2003) as

$$
\mathrm{SR}=-\sum_{s=0}^{\infty} \delta^{s-t_{0}} E_{t_{0}}\left[\frac{Y_{t_{0}+s}-Y_{t_{0}+s}^{*}}{Y_{t_{0}+s}^{*}}\right] \approx-\sum_{s=0}^{\infty} \delta^{s-t_{0}} E_{t_{0}}\left[\ln Y_{t_{0}+s}-\ln Y_{t_{0}+s}^{*}\right]=-\sum_{s=0}^{\infty} \delta^{s-t_{0}} E_{t_{0}} y_{t_{0}+s}
$$

where $t_{0}$ - time of the disinflation monetary policy action, $Y, Y^{*}-$ real and potential output level, $E_{t}-$ expectations operator based upon information available at time $t, \delta$ - discount factor.

Using the chosen calibrated coefficients from our illustrative derivation of SR, we would reach the SR value of $2.3 \%$. More important, however, is the fact that after simplifying equation (8) by dropping the discount factor $\delta$, we obtain a SR coefficient depending only on the parameter $\gamma$ (see also theoretical background provided by Cecchetti and Rich, 1999 or Leitemo and Røste, 2003) which is the inverse approximation of nominal inertia within the economy. After this amendment (dropping of $\delta$ ) the parameter $\theta$ does not have any influence on the SR coefficient. Similarly, 
parameters $\rho, \alpha$ and $\beta$ would only serve to set the chosen trajectory of inflation and output gap. As the central bank's objective function (4) only includes inflation and output, parameters $\rho, \alpha$ and $\beta$ cannot influence the SR coefficient. We may therefore conclude that the key factor of disinflation costs analysis is the parameter $\gamma$. If the nominal inertia within the economy is high (i.e. $\gamma$ is low), than even major fluctuations of GDP around the potential product level cannot influence the inflation significantly.

\section{Empirical Results}

The existence of disinflation costs has been the cause of rather complex discussions among economists. The objective of such discussions usually consisted of finding a plausible way to minimise such costs. Some authors analysed different disinflation speeds, others were looking for inflation persistence causes and relevant remedies in order to minimize the disinflation costs. Similarly, complex discussion sprung up about proper SR coefficient computational form (or its derivation) that would be suitable for analysis of real economies.

For example, the main disadvantage of the SR (8) equation derived from the model (1) to (4) is that it ignores non-monetary factors influencing inflation and output. When we work with time series of real economies (such as the Czech Republic, euro area, USA) we cannot assume that all output and inflation fluctuation within the relevant period are caused by monetary policy. A simple estimation of mutual dependence of inflation and output therefore cannot provide a reasonable approximation of the SR coefficient. First of all, we need to identify and isolate monetary policy from other relevant shocks (fiscal, random, etc.). Vector autoregression (VAR) models and impulse response (IR) analysis based on Blanchard-Quah (BQ) decomposition (see Blanchard and Quah, 1989) are usually perceived as the best tools to perform such task.

Another step preceding proper SR estimation should be the differentiating between two basic categories of monetary policy setting and performing: A portion of the actions taken by the central bank is not performed on an autonomous (discretionary, ad hoc) basis, but somewhat automatically. Standard monetary policy measures are planned and prepared in advance to be used in reaction to common types of shocks, in order to minimise the negative impact of shocks. Such monetary policy has an endogenous character, central bank systematically reacts to standard shocks. Shifts in monetary policy form a different category of monetary policy shocks: among others, changes of inflation target or change of weights assigned to different variables of the central bank's objective function belong to this category. In order to differentiate between systematic and non-systematic monetary policy, we use structural VAR (SVAR) models, as proposed by Amisano and Giannini (1997).

Choosing of the period used for empirical analysis is another important issue for SR calculation. Some authors (e.g. Ball, 1994) use only disinflation periods in order to calculate the SR, where they suppose that restrictive monetary policy led to simultaneous decrease of output and inflation. However, in our opinion this precarious exclusion of certain time periods from the SR calculation lacks proper theoretical justification. Asymmetric results of monetary policy actions are not a commonly accepted fact. Herewith we assume that monetary restriction and expansion reflect on inflation and output without any systematic difference, except for the direction or "sign" of the effect incurred. Therefore, both monetary restriction and monetary expansion periods have the same informational value for SR calculation. 
Last but not least, accuracy of the estimates is a key factor for calculation and interpretation of the SR coefficients for real economies. Many authors do not provide their SR ratio estimates with accuracy information, making almost impossible any serious judgement of their studies. Simulation methods are probably the best way to provide confidence limits for the SR. After generating roughly hundredths of time series with characteristics corresponding to the endogenous variables of the macroeconomic model (mostly in the form of VAR representation), we estimate the model for all generated sets of dummy endogenous variables, compute all the respective impulse response functions of output and inflation and than we compute the SR for each simulated set. Finally, we calculate standard error and confidence limits (for a chosen level of probability) from the group of simulated SR coefficients.

The simulation procedure described above, however, also has some drawbacks: simulations frequently generate explosive behaviour of IR functions or SR coefficients with values exceeding $\pm 100 \%$ (see e.g. Cecchetti and Rich, 1999 or Leitemo and Røste, 2003). It is therefore necessary to manually sort through the simulations and exclude implausible results from further calculation. This approach introduces subjective judgement into SR accuracy estimation and limits its reliability. Also, simulated SR coefficients mostly have non-normal distribution. In our case, the influence of subjective judgment on the indicators of SR accuracy would be too significant. Therefore, we have used a different approximation of the SR reliability, derived from the variance of cumulative IR function (based on Choleski decomposition) of output. This approximation is not unbiased, but given the circumstances we consider it to be consistent and satisfying our needs.

This paper provides two alternative estimates of SR for the Czech economy. The estimates are based on relatively simple, but transparent and verified models, i.e. their VAR and vector moving average (VMA) representations. We have used a twovariable model by Cecchetti (1994) and a three-variable model by Shapiro and Watson (1988). ${ }^{1)}$ As we use real data in our models - variables are not measured as deviations from their long-term equilibrium - we had to amend the SR formula accordingly.

Cecchetti (1994) designed his model based on a generalization of the Phillips curve. Using the VMA representation, Cecchetti's two-equation model of inflation and output may be written as

$$
\left[\begin{array}{c}
\Delta y_{t} \\
\pi_{t}
\end{array}\right]=\boldsymbol{A}(L)\left[\begin{array}{c}
\epsilon_{t}^{y} \\
\epsilon_{t}^{\pi}
\end{array}\right]=\left[\begin{array}{ll}
A_{11}(L) & A_{12}(L) \\
A_{21}(L) & A_{22}(L)
\end{array}\right]\left[\begin{array}{c}
\epsilon_{t}^{y} \\
\epsilon_{t}^{\pi}
\end{array}\right]=\left[\begin{array}{ll}
\sum_{i=0}^{\infty} a_{11}^{i} \epsilon_{t-i}^{y} & \sum_{i=0}^{\infty} a_{12}^{i} \epsilon_{t-i}^{\pi} \\
\sum_{i=0}^{\infty} a_{21}^{i} \epsilon_{t-i}^{y} & \sum_{i=0}^{\infty} a_{22}^{i} \epsilon_{t-i}^{\pi}
\end{array}\right]
$$

where $\Delta y_{t}$ - real quarterly GDP (prices of 1995) seasonally adjusted by moving averages and expressed in the form of relative quarterly differences, $\pi_{t}-$ inter-quarter inflation rate in percentage points, based on CPI and seasonally adjusted by moving averages, $i$ - index of the sequence of coefficients, $\boldsymbol{A}(L)-2 \times 2$ matrix of polynomials in the lag operators $a_{j k}^{i}, \in_{t}^{y}-$ supply shock; random element affecting the aggregate supply, $\in_{t}^{\pi}$ - demand shock; random element affecting the aggregate demand.

1) Gali (1992) and Corbo et al. (2001) have estimated SR from 4 and 5-dimensional VAR models. 
We shall start our analysis by estimation of the corresponding two-equation VAR model. The number of lags used $j=2$ was chosen by the AIC and SIC information criteria. The estimation itself of the model (9) was performed on data for the Czech economy from the period 1994:Q3 to 2002:Q4:

$$
\begin{aligned}
& \Delta \hat{y}_{t}=+1.401^{\star} \Delta y_{t-1}-0.7393^{*} \Delta y_{t-2}+0.1014^{*} \pi_{t-1}+0.0534^{*} \pi_{t-2} \\
& \begin{array}{llll}
(\mathrm{SE}) & (0.136) \quad(0.173) & (0.304)
\end{array}
\end{aligned}
$$

$\bar{R}^{2}=0.90 ; \mathrm{DW}=1.81 ;$ Durbin $h=0.90$

$$
\begin{aligned}
& \hat{\pi}_{t}=+0.172 * \Delta y_{t-1}+0.03656 * \Delta y_{t-2}+1.375 * \pi_{t-1}-0.5123 * \pi_{t-2} \\
& \begin{array}{llll}
(\mathrm{SE}) \quad(0.054) \quad(0.0693) & (0.121) & \text { (0.106) }
\end{array}
\end{aligned}
$$

$\bar{R}^{2}=0.99 ; \mathrm{DW}=1.71 ;$ Durbin $h=1.18$

After estimating the VAR model, we may proceed to identification of the supply and demand shocks from the VMA representation (9). Even though structural shocks are not directly measurable, they may be calculated using additional identifying restrictions. We shall therefore distinguish the demand and supply shocks using Blanchard-Quah identifying restriction. For the equation (9), we may write this restriction as

$$
c_{12}=0 \text { or } \boldsymbol{C}=\left[\begin{array}{ll}
c_{11} & 0 \\
c_{21} & c_{22}
\end{array}\right],
$$

i.e. demand shocks in the model (9) have no long-term impact on the level of real output. We shall now associate the non-systematic changes in monetary policy with the demand shocks $\in_{t}^{\pi}$. Although this is a significant simplification, it is a relatively common approach to SR calculation (see e.g. Cecchetti and Rich, 1999). Now we can rewrite the SR formula as

$$
\operatorname{SR}_{\epsilon^{\pi}}(\tau)=\frac{\sum_{j=0}^{\tau}\left(\frac{\partial y_{t+j}}{\partial \epsilon_{t}^{\pi}}\right)}{\left(\frac{\partial \pi_{t+\tau}}{\partial \epsilon_{t}^{\pi}}\right)}=\frac{\sum_{i=0}^{\tau} \sum_{j=0}^{i} a_{12}^{i}}{\sum_{i=0}^{\tau} a_{22}^{i}}
$$

where $\mathrm{SR}_{\epsilon^{\pi}}(\tau)$ modified SR for use in real economies and $\tau$ - time limit for calculation of the effects of shock $\in_{t}^{\pi}$.

The main difference between equations (8) and (13) is that we do not use an "infinite" horizon for calculating the effect of the shock on inflation and accumulated output loss. Instead, we use an arbitrary and relatively short horizon $\tau$. We set here the value of $\tau$ as 20 quarters, i.e. five years. We may therefore interpret our SR coefficient (13) as the ratio of relative cumulative output loss to inflation percentage decrease reached after the incurred monetary shock at the end of the period analysed.

The computation itself of the SR for the Czech economy is now a relatively simple operation. Based on the estimations (10) and (11) we use Blanchard-Quah identifying restriction (12) and we generate impulse response functions of endogenous variables for the structural shocks $\epsilon_{t}$; for SR calculation, we may limit ourselves to IR functions for the $\in_{t}^{\pi}$ shock. Graph 3 shows the IR and cumulative IR function of the Czech output after non-systematic monetary restriction and Graph 4 shows the reaction of the Czech inflation to the same monetary shock $\in_{t}^{\pi}$. 
Graph 3

The Effect of Monetary Restriction on Output

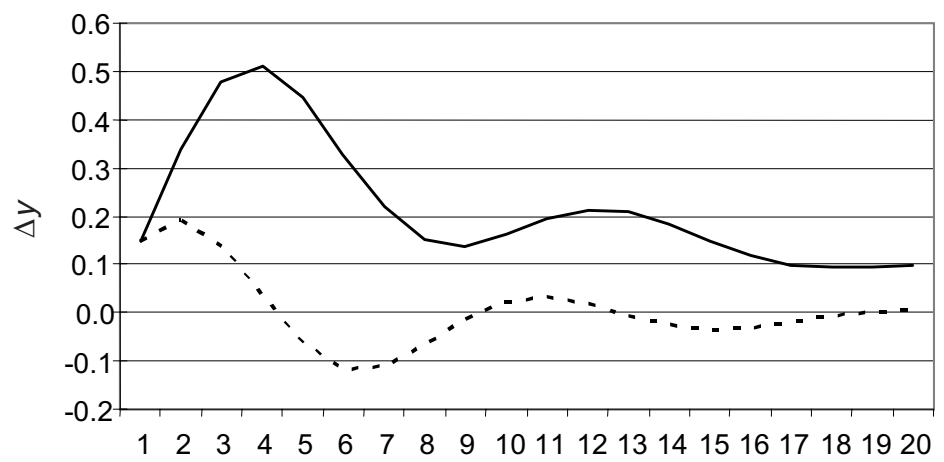

... IR function of the variable $\Delta y$ and shock $\in_{t}^{\pi}$

- Cumulative representation of the IR function

Graph 4

The Effect of Monetary Restriction on Inflation

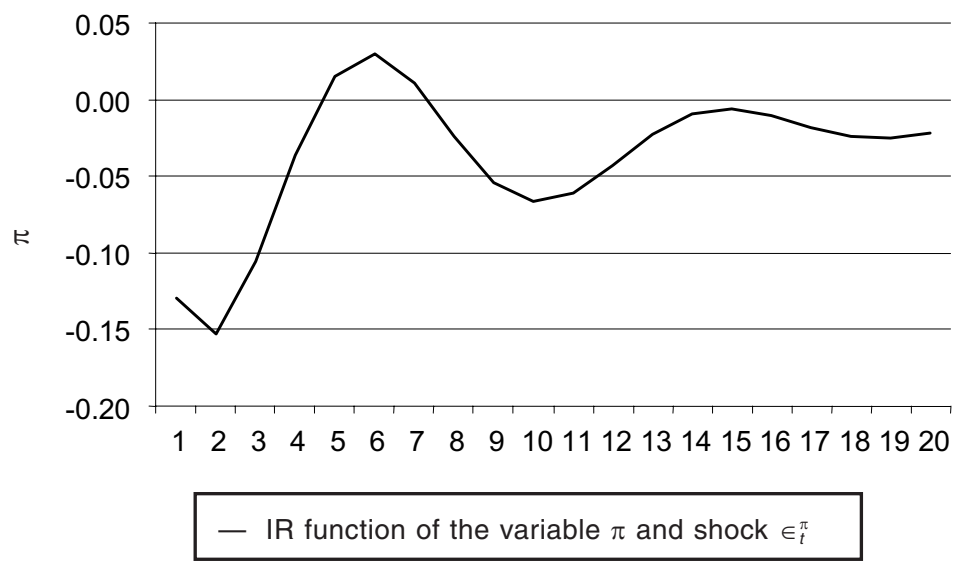

From Graph 4 we may see that the IR function of inflation behaves almost perfectly according to theoretical expectations. After primary oscillation, the IR curve converges to a new equilibrium level, lower than the original level. The only unexpected feature of the IR function in Graph 4 is the magnitude of the first oscillation (ending at time $t=10$ ) that is probably higher than similar reactions to be observed in standard (non-transition) economies. In contrast, Graph 3 shows that the IR function of GDP after monetary restriction has a wrong sign (direction). The interpretation of such IR function is a theoretical problem and we think that this behaviour reflects the transition character of the Czech economy.

For this model calculated for the Czech economy we have reached SR value of $-4.466 \%$. Consistent (but biased) estimate of the SR standard error (derived by Monte Carlo simulation with 1,000 repetitions and using Choleski decomposition) is 
$\hat{\sigma}=1.194 \%$. The corresponding approximation of the $95 \%$ confidence interval of $\mathrm{SR}$ ranges from -6.81 to -2.13 . Although a negative $\mathrm{SR}$ coefficient value may be backed by economic theory, in case of the Czech economy we see this rather as a direct consequence of the transition character of the economy.

The previous model does not allow for distinction between the individual types of demand shocks, therefore the estimation does not make any difference between monetary and fiscal shocks, final consumption or investment changes, etc. Shapiro and Watson (1988) therefore designed a model that differentiates the aggregate demand shocks into two types: IS and LM shocks. In order to calculate the SR, we assume herewith that non-systematic changes in monetary policy correspond to LM shocks, i.e. to $\in_{t}^{\mathrm{LM}}$ from the equation (14). After small amendment of the three-equation Shapiro-Watson model - like Cecchetti and Rich (1999) we drop the exogenous oil price variable - we may write the model using VMA representation as

$$
\left[\begin{array}{c}
\Delta y_{t} \\
\pi_{t} \\
\left(i_{t}-\pi_{t}\right)
\end{array}\right]=\boldsymbol{A}(L)\left[\begin{array}{c}
\epsilon_{t}^{y} \\
\epsilon_{t}^{\mathrm{LM}} \\
\epsilon_{t}^{\mathrm{IS}}
\end{array}\right]
$$

where $i_{t}-$ nominal quarterly yield from short term assets, calculated from seasonally adjusted p.a. interest rate PRIBOR $3 \mathrm{M}$ valid for the respective period, $\left(i_{t}-\pi_{t}\right)-$ ex-post real quarterly yield from short term assets, $\epsilon_{t}^{\mathrm{y}}-$ supply shock, $\in_{t}^{\mathrm{LM}}-\mathrm{LM}$ shock, $\in_{t}^{\text {IS }}$ - IS shock, and the remaining elements of the model (14) correspond to equation (9). Using the information criteria we have set the number of lags for estimation of the corresponding VAR to $j=2$. The estimation of the three-variable VAR(2) model was performed as follows

$$
\begin{aligned}
& \Delta \hat{y}_{t}=+1.369^{\star} \Delta y_{t-1}-0.7855^{\star} \Delta y_{t-2}+0.615^{\star} \pi_{t-1}-0.460^{*} \pi_{t-2} \\
& \begin{array}{llll}
(\mathrm{SE}) & (0.144) \quad(0.317) & \text { (0.694) }
\end{array} \\
& +\underset{(0.684)}{0.585^{*}}\left(i_{t-1}-\pi_{t-1}\right)-\underset{(0.568)}{0.4892^{*}}\left(i_{t-2-}-\pi_{t-2}\right)
\end{aligned}
$$

$\bar{R}^{2}=0.90 ; \mathrm{DW}=1.74 ;$ Durbin $h=1.36$

$$
\begin{aligned}
& \hat{\pi}_{t}=+0.174^{*} \Delta y_{t-1}+0.149^{*} \Delta y_{t-2}+1.427^{*} \pi_{t-1}-0.568^{*} \pi_{t-2} \\
& \begin{array}{llll}
(\mathrm{SE}) & (0.056) \quad(0.075) & (0.272) & \text { (0.2666) }
\end{array} \\
& +0.001^{*}\left(i_{t-1}-\pi_{t-1}\right)+0.0464^{*}\left(i_{t-2}-\pi_{t-2}\right) \\
& \text { (0.268) (0.223) }
\end{aligned}
$$

$\bar{R}^{2}=0.99 ; \mathrm{DW}=1.94 ;$ Durbin $h: \mathrm{NA}$

$$
\begin{aligned}
& \left(i_{t} \hat{-} \pi_{t}\right)=-0.045^{\star} \Delta y_{t-1}-0.1144^{\star} \Delta y_{t-2}+0.3445^{\star} \pi_{t-1}-0.1967 * \pi_{t-2} \\
& \begin{array}{lllll}
(\mathrm{SE}) & (0.0536) & (0.071) & \text { (0.259) }
\end{array} \\
& +1.582 *\left(i_{t-1}-\pi_{t-1}\right)-0.684 *\left(i_{t-2}-\pi_{t-2}\right) \\
& (0.255) \quad(0.212)
\end{aligned}
$$

$\bar{R}^{2}=0.98 ; \mathrm{DW}=1.83 ;$ Durbin $h: \mathrm{NA}$

We may now compute the IR functions necessary for SR calculation. In order to identify the non-observable structural shocks, we shall again use a Blanchard-Quah restriction of the type (12). In this case, the identifying (zero value) condition on the $3 \times 3$ matrix $\boldsymbol{C}$ holds for coefficients $c_{12}, c_{13}, c_{23}$ from the equation (14). Graphs 5 and 6 show the IR functions of the Czech inflation and output after a restrictive moneta- 
ry shock $\in_{t}^{\mathrm{LM}}$. Time period $\tau$ for the SR calculation is again set to 20 . From both graphs we may see that IR dynamics corresponding to the restrictive monetary shock is similar to previous model. The inflation reacts as expected to the shock incurred (see Graph 6), but output deviates from theoretical expectations (5) - mostly during the first five periods after the exogenous shock. This output IR development then leads to unexpected cumulative IR output function and - once again - to negative SR value.

Graph 5

The Effect of Monetary Restriction on Output

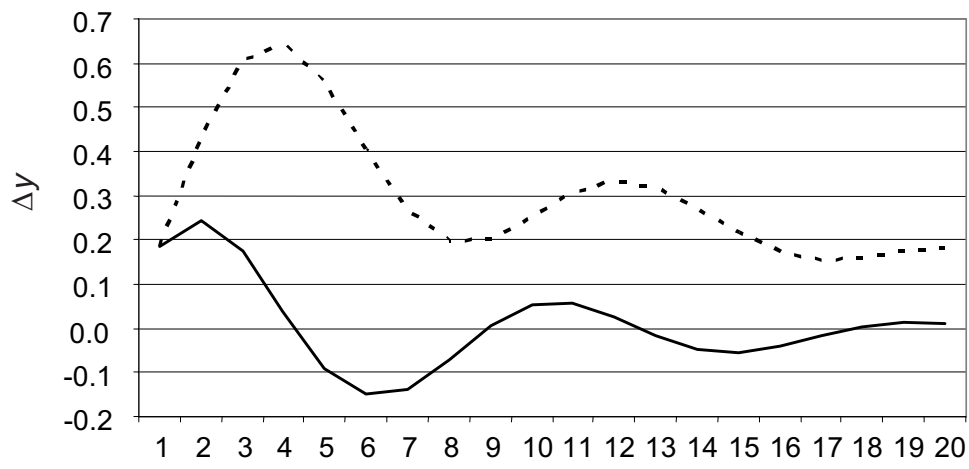

- IR function of the variable $\Delta y$ and shock $\epsilon_{t}^{\mathrm{LM}}$

... Cumulative representation of the IR function

Graph 6

The Effect of Monetary Restriction on Inflation

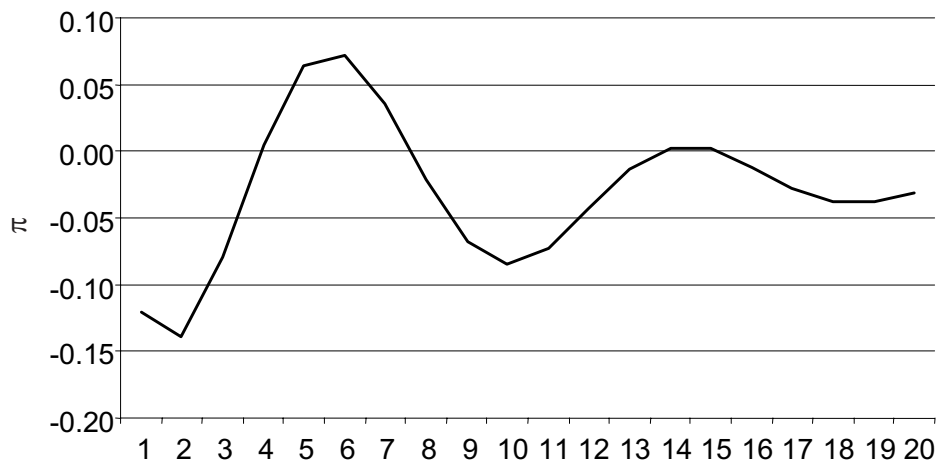

- IR function of the variable $\pi$ and shock $\epsilon_{t}^{\mathrm{LM}}$

Sacrifice ratio coefficient was calculated using the IR functions from the model estimation (15) to (17) and we have obtained $S R=-5.82 \%$. Confidence levels were also calculated (using the previously described approach), with standard error $\hat{\sigma}=$ $3.643 \%$ and relevant $95 \%$ confidence interval between -12.960 and +1.320 . 
There are two main conclusions standing out from their SR calculation. First, stratification of the demand shock into two components $\left(\epsilon_{t}^{\mathrm{LM}}\right.$ and $\left.\epsilon_{t}^{\mathrm{IS}}\right)$ let to significant increase in the standard error of the estimate. Second, the zero value of the SR lies within the $95 \%$ confidence interval; hence we cannot rule out the possibility of costless disinflation in the Czech economy. Both conclusions described here are reflecting similar conclusions, reached by Cecchetti and Rich (1999) during their study of the U.S. economy.

We have used one-step residuals method to analyse the impact of the transient character of the Czech economy on our results. Time series used for estimation of the models (9) and (14) were divided in two parts: (1994:Q1 - 1998:Q2 and 1998:Q3 - 2002:Q4) and subsequently the estimations of the models and the SR calculation were performed on both parts of the halved time series. The results obtained were compared against each other and against the full sample and we have reached the conclusion that the estimates are relatively stable throughout the whole period analysed here.

\section{Conclusion}

Based on the two estimated models and their respective SR derivations, we may summarize our conclusions into few topics. In order to provide a complete perspective, we compare our results for the Czech economy with results published on other economies by Cecchetti and Rich (1999) or Leitemo and Røste (2003).

By adding new variables to the model in order to better distinguish between the individual parts of the aggregate demand, we experience a significant increase in standard errors and confidence limits of the SR estimate. When we analyse both models from the accuracy of the SR estimate point of view, we see that the results are very sensitive to the way of definition of monetary shocks. As Cecchetti and Rich (1999) have reached the same conclusions for the U.S. economy, we may conclude that this insufficient accuracy of the estimates is due to the calculation method itself (based on IR functions), rather than due to the transition character of the Czech economy.

Even though the individual estimates of the SR are not accurate enough, there is a good probability that SR for the Czech economy was negative during the period analysed, with relatively low absolute value. Leitemo and Røste (2003) have reached similar conclusion when analysing selected small open OECD economies. Many such countries have low SR ranging roughly from -1 to +1 . This conclusion is valid for countries such as Norway, Sweden, Netherlands (some estimates) and UK (some estimates). On the other hand, high SR coefficient of $+4 \%$ and more was estimated for countries such as Canada (some estimates) and Netherlands (some estimates).

We did not prove any significant bias in the SR estimates for the Czech economy that would be due to changes in macroeconomic relationships. The transient character of our economy was reflected mainly in unexpected behaviour of the estimated IR functions of output.

Finally, we may conclude that using VAR models and real time series of economic variables only allows us to generate IR estimates of indicative value that are generally not suitable for real setting of monetary policy. In our opinion, with longer time series available (within 5 or 10 years from now) we might be able to get results with accuracy features largely improved. Currently, we do not consider the calibration of coefficients or inclusion of non-measurable subjectively chosen variables (such as output gap) to be an adequate way for improving the accuracy of estimation results. Even though SR coefficients with lower standard errors may be obtained that 
way, this advantage is outweighed by the inclusion of strong subjective element into the model estimation.

Our results of the SR estimation indicate that the Czech SR coefficient should have a relatively low absolute value. Also, given the transition character of the Czech economy, our SR coefficient has a negative value. We may therefore assume that if Czech National Bank decides to incur monetary restriction (preparing our economy for the EMU accession), such action would not have long-term (perhaps neither medium term) significant negative impact on output.

References

Amisano, G., Giannini, C. (1997), Topics in Structural VAR Econometrics (2nd ed). New York: Springer Verlag.

Ball, L. (1994), "Credible Disinflation with Staggered Price-Setting." American Economic Review, 84, pp. 282-289.

(1999), "Policy Rules for Open Economies", in Taylor, J., ed., Monetary Policy Rules. NBER Conference Report Series, Chicago University Press, pp. 127-156.

Blanchard, O. J., Quah, D. (1989), "The Dynamic Effects of Aggregate Demand and Supply Disturbances." American Economic Review, 79, pp. 655-673.

Cecchetti, S. G. (1994), "Comment", in Mankiw, N. G., ed., Monetary Policy. Chicago: University of Chicago Press, pp. 188-193.

Cecchetti, S. G., Rich, R. W. (1999), "Structural Estimates of the U.S. Sacrifice Ratio." Federal Reserve Bank of New York.

Corbo, V., Moreno, O., Schmidt-Hebbel, K. (2001), "Assessing Inflation Targeting after a Decade of World Experience." Central Bank of Chile, mimeo.

Fuhrer, J. C. (1995), "The Persistence of Inflation and the Cost of Disinflation." New England Economic Review (January/February), Federal Reserve Bank of Boston, pp. 127-159.

Gali, J. (1992), "How Well Does the IS-LM Model Fit Postwar U.S. Data?" Quarterly Journal of Economics, 107 (2), pp. 709-738.

Leitemo, K., Røste, O. B. (2003), "Measuring the Sacrifice Ratio: Some International Evidence." Norwegian School of Management (http://www.economics.no/preparation.htm\#sacrifice).

Shapiro, M. D., Watson, M. W. (1988), "Sources of Business Cycle Fluctuations", in Blanchard, O. J., Fisher, S.: NBER Macroeconomics Annual. Cambridge, MA: MIT Press, pp. 111-148.

Taylor, J. (1979), "Staggered Wage Setting in a Macro Model." American Economic Review, 69, pp. 108-113. 